\title{
A simplified technique for conditioning respiratory mouth movements in fish'
}

RICHARD R. FAY $Y^{2}$ and JOHN R. MacKINNON, Connecticut College, New London, Conn. 06320

This report describes a simple technique and restraining device for investigating classically conditioned inhibition of respiration in the fish. The restraining device is seen as having wide applicability for investigations which necessitate the immobilization of the $S$.

Classically conditioned inhibition of respiration has been reliably demonstrated in the restrained fish, and has provided a useful basis for investigating certain learning and sensory phenomena (Fay, 1968; Otis, Cerf, \& Thomas, 1957; Woodard, 1967). One method for recording respiratory movements involves the placement of a flexible metal probe along one operculum, and the mechanical oscillations are converted into electrical energy by means of a suitable transducer (Otis et al, 1957; Woodard, 1967). The electrical activity can then be amplified and recorded on a standard inkwriter.

In a recent investigation of auditory discrimination in the goldfish, Fay (1968) utilized a modification of the above technique for measuring respiratory activity. The present report describes a simple method for recording respiratory mouth movements in small (5-7 in.) goldfish. The response measure may be analyzed in terms of rate, amplitude, and latency, and is relatively free from artifacts due to lateral head or body movements.

The basic restraining apparatus (Fig. 1) is a simple and easily constructed device which effectively immobilizes the $S$ and minimizes the opportunity for competing behavior. The restrainer consists of a $1 / 4-i n$. rectangular Plexiglas base with three 1/8-in. brass rods bolted along each side. The body of the fish, posterior to the head and opercula, is firmly held in two cellulose sponges which are inserted between the brass rods. The inside surface of the sponges is hollowed out to provide a more comfortable fit. Steel electrodes which deliver shock across the caudal area of the fish are embedded in each sponge, and insulated leads from the electrodes may be connected to any shock generator. In order to keep the fish's head in a rigid position, a nose ring made of coat hanger wire wrapped in cheesecloth is connected to the front of the restrainer by means of telescoping brass tubing. The ring is pushed over the nose of the fish until it rests lightly between the mouth and opercula. It is essential that the nose ring be placed so that it does not impede respiratory movements of the mouth.

Any high output crystal phonograph cartridge may be used as the movement transducer. The cartridge is supported on its side, above and in front of the restrainer (see Fig. 1). The rigid brass strip supporting the cartridge is connected to the restrainer by means of short lengths of brass tubing fitted over the forward pair of brass rods. A light steel spring is soldered to the tip of the cartridge needle to insure a dampened mechanical connection with the fish's lower lip. A short length of nylon monofilament thread with a small nylon "stop" attached to one end is passed up through the thin cartilage behind the bony portion of the fish's lower lip. The free end of the nylon thread is then inserted between the coils of the spring and pulled taut so as to provide a direct connection between the cartridge needle and the lip without impeding respiratory mouth movements. The cartridge output is then connected to a $\mathrm{dc}$ amplifier and suitable recording device.

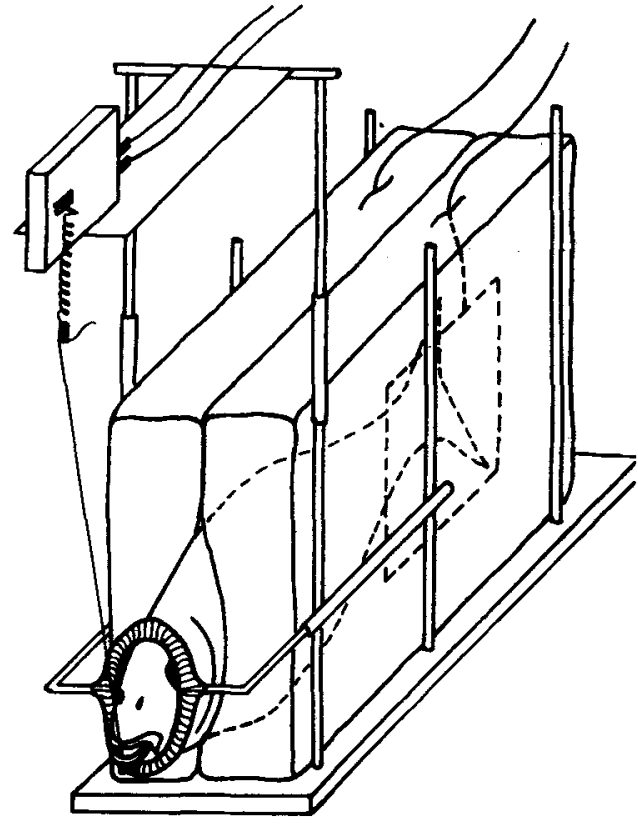

Fig. 1. Restraining and transducing apparatus, showing the frame and sponge holders with embedded shock electrodes, the adjustable nose piece, and the mounted crystal phonograph cartridge.

The entire restraining unit may be attached to a weighted base which rests on the bottom of the experimental tank, or may be supported from above. It is important that the phonograph cartridge remain above the water level unless it is suitably waterproofed. Metal structural parts should be coated with Epoxy paint in order to prevent corrosion.

A goldfish restrained in this manner stops struggling and achieves a steady breathing rate within $10 \mathrm{~min}$. In one of a series of experiments, four 6-in. goldfish were given 20 delay conditioning trials, with an intertrial interval of approximately 2 min. On each trial, the conditioned stimulus (CS), a low frequency tone of moderate intensity, was presented for $5 \mathrm{sec}$. Overlapping and terminating with the CS was a train of square-wave shock pulses of 1 -sec duration. A continuous graphic record of responding was obtained by means of a

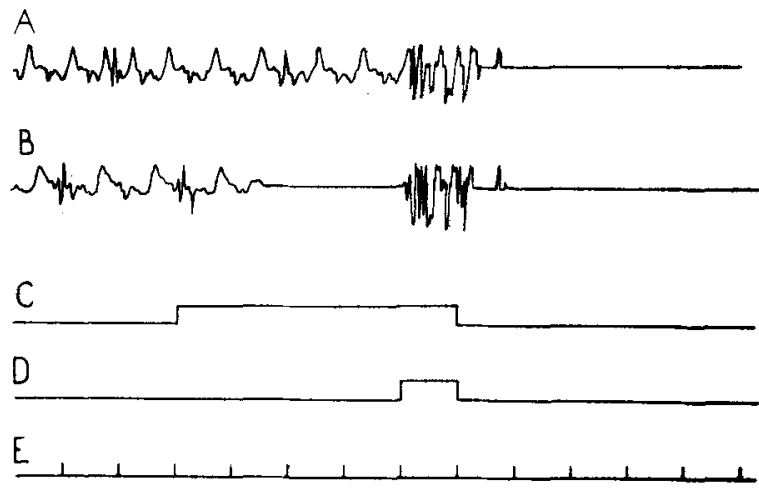

Fig. 2. Tracing of a typical record for an individual $S$ on Trials 1 and 10. (A) Conditioning Trial 1; (B) Conditioning Trial 10; (C) CS, a 5-sec tone; (D) US, a 1 -sec shock; (E) time in seconds. 
Sanborn Viso-Cardiette, Model 572-M. Tracings of a representative record for a single $S$ on Trials 1 and 10 are shown in Fig. 2. The typical unconditioned response (UCR) was a complete suppression of respiration, often lasting several seconds. A reliable and unambiguous anticipatory conditioned response (CR) was obtained in all Ss following relatively few CS-UCS pairings (see Fig. 2).

The restraining device, in particular, should prove useful to researchers using classical conditioning procedures with fish. As well as minimizing competing responses, the restrainer provides an effective means for insuring the position of the fish with respect to a visual or auditory stimulus. The device has the practical advantage of being inexpensive and simple to construct.

\section{REFERENCES}

FAY, R. R. Auditory sensitivity of the goldfish within the acoustic near field. Unpubliched Master's thesis, Connecticut College, 1968.

OTIS, L. S., CERF, J. A., THOMAS, G. J. Conditioned inhibition of respiration and heart rate in the goldfish. Science, 1957, 126, 263-264.

WOODARD, W. T. Kamin effect in goldfish. Paper presented at the annual meeting of the Psychonomic Society, Chicago, October, 1967.

\section{NOTES}

1. This report describes a technique employed in a thesis submitted by the senior author in partial fulfillment of the requirements for the M.A. degree in psychology at Connecticut College.

2. Now at Princeton University.

\title{
Two improvements for the
}

\section{Econo-Cage \#110 metabolism unit'}

\author{
ROBERT BOICE, Ohio University, Athens, Ohio 45701
}

The Econo-Cage metabolism unit is improved by replacing a breakable plastic rod which holds the feeder screen in place and by collecting feces on a removable screen instead of from the urine contaminated base.

An attractive new metabolism cage, the Econo-Cage No. 110 metabolism unit, ${ }^{2}$ can be made more effective with two simple improvements. First, the "V" shaped food hopper cover incorporates a plastic rod designed to prevent the animal from pulling the cylindrical wire food-access unit into his living chamber. The plastic rod is easily broken by laboratory rats, allowing their escape through the food hopper. A 3-16 x $11 / 2$-in. screw with the nut placed inside the " $\mathrm{V}$ " (Fig. 1-A) replaces the plastic rod. Especially vigorous rodents may necessitate the use of adhesive tape wound around over the opening of the food hopper to hold the hopper cover in place.

Second, the collection of feces is implemented by the use of a one-piece removable screen unit with its surface 1 in. above the plastic base and with a 13/4-in. hole in the center to accommodate the urine receptacle (Fig. 1-B). The screen unit consists of two pieces of window screening, one circular with a diameter of $7 \frac{1}{2}$-in. and the other a 1-in. strip which is soldered to the edge of the first. The screen unit permits the removal of all feces at once, without scraping, and prevents contamination by urine which overflows from its receptacle onto the plastic base. The approximate 30-cc capacity of the urine receptacle is inadequate for daily measures of some small rodents such as Neotoma micropus which may urinate $120 \mathrm{cc}$ in $24 \mathrm{~h}$.

$$
\text { NOTES }
$$

1. This note is based on research supported by an NSF grant to Frank A. Logán.

2. Manufacturer: Maryland Plastics, Inc., 9 East 37th Street, New York, N. Y. 10016.

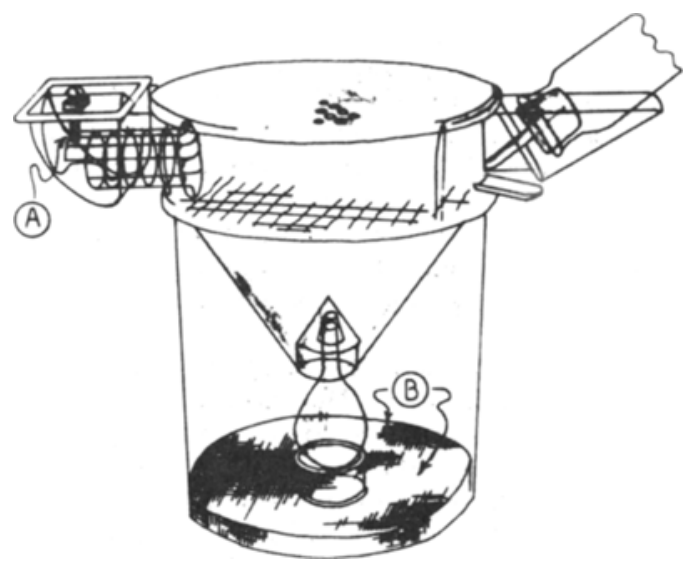

Fig. 1. Idealized view of metabolism unit showing screw and nut (A) which replace the plastic rod of the food hopper cover and the removable screen unit (B). 